\title{
THE CLINICAL, ARTHROSCOPIC AND HISTOLOGICAL FINDINGS AFTER REPLACEMENT OF THE ANTERIOR CRUCIATE LIGAMENT WITH CARBON-FIBRE
}

\author{
N. RUSHTON, D. J. DANDY, C. P. E. NAYLOR \\ From Addenbrooke's Hospital, Cambridge, and Newmarket General Hospital
}

\begin{abstract}
Thirty-nine patients underwent reconstruction of the anterior cruciate ligament with carbon-fibre and a MacIntosh repair; all had a negative pivot shift test after operation. Some patients had persistent pain, mild effusion and synovial thickening; in 10 of these patients the symptoms warranted arthroscopic examination and biopsy at a mean of 16.9 months after the repair. Arthroscopy revealed that the carbon-fibre had not induced the formation of a "new ligament" and that the repair was merely covered by a thin, fibrous sheath. Histological investigations confirmed this finding, with only a suggestion of a fibroblastic response to carbonfibre found in two patients. Particles of carbon-fibre were found scattered through the knees. Synovitis and breakdown of the skin over subcutaneous carbon-fibre complicated treatment. Failure of the carbon-fibre to bond to bone was detected radiographically.
\end{abstract}

Carbon-fibre has been recommended as a suitable material for replacing the anterior cruciate ligament. We report the clinical, arthroscopic and histological findings of 10 patients who experienced pain and discomfort after replacement of the anterior cruciate ligament with carbon-fibre. We discuss the shortcomings of using carbon-fibre and question the widely canvassed view that carbon-fibre may be augmented or replaced by fibrous tissue to produce a "new ligament".

\section{PATIENTS AND METHOD}

During a period of three years, 39 patients aged between 18 and 39 years (mean 25.6 years) had their ruptured anterior cruciate ligaments replaced with carbon-fibre (Grafil A-S made by Courtaulds). The carbon-fibre was passed across the joint along the anatomical path of the ruptured anterior cruciate ligament; no attempt was made to surround the carbon-fibre with soft tissue. In addition, each patient had a MacIntosh lateral substitution repair performed at the same time (Ireland and Trickey 1980). All the operations were performed by one surgeon (DJD).

The progress of the patients after operation was generally satisfactory except for persistent pain, mild effusion and synovial thickening in some knees; 10 patients had enough pain and discomfort to require an arthroscopic investigation. The time from repair to arthroscopy and biopsy was between 12 and 30 months (mean 16.9 months) and the follow-up after biopsy was between 12 and 30 months (mean 16.7 months). All 10 patients were relatively young (mean 26.5 years, range 18 to 38 years) and had suffered a typical injury 2 to 60 months before repair of the ligament (mean 25.2 months); all had a

D. J. Dandy, FRCS, Consultant Orthopaedic Surgeon Newmarket General Hospital, Exning Road, Newmarket, Suffolk, England.

N. Rushton, MA, FRCS, Clinical Lecturer in Surgery (Orthopaedics), University of Cambridge

C. P. E. Naylor, MA, MB, BChir, Senior Registrar in Histopathology Addenbrooke's Hospital, Hills Road, Cambridge CB2 2QQ, England. Requests for reprints should be sent to $\mathrm{Mr} \mathrm{N}$. Rushton.

(C) 1983 British Editorial Society of Bone and Joint Surgery $0301-620 \mathrm{X} / 83 / 3032-0308 \$ 2.00$ negative pivot shift test after operation. Apart from the persistent pain, effusion and synovial thickening these 10 patients were similar to the other 29 patients having carbon-fibre repair.

Tissue obtained from the 10 knees at biopsy was fixed in formalin, embedded in wax or resin, and cut into five-micrometre sections. The sections were then stained with haematoxylin and eosin; Perls' test for haemosiderin was also performed. Gram's stain was performed where appropriate and was negative.

\section{RESULTS}

All 10 patients had synovitis with evidence of particles of carbon-fibre in the joint which occasionally stained the articular surface and the menisci. The femoral notch of some patients contained inflamed synovium which was stained black. In some patients a "new ligament" appeared to have formed but gentle probing with a blunt hook revealed this to be a thin, fibrous sheath covering unchanged carbon-fibre tow.

Three patients developed ulceration of the skin over subcutaneous knots of carbon-fibre which became superficially infected 7,9 and 12 months after operation. There was no evidence of infection tracking along the carbonfibre tow, and the infection resolved quickly after removal of the knots in two patients, and after removal of the whole carbon-fibre prosthesis in the third.

All of the patients who had radiographs taken after operation were seen to have distinct corticated holes surrounding the carbon-fibre tow where it passed through the bone; these holes were larger than those originally drilled and their presence was unrelated to any superficial infection (Fig. 1). There was no evidence of incorporation of the carbon-fibre into the bone.

Histological findings. In two patients, where in small areas there was a suggestion that the fibroblasts were orientated parallel to the carbon-fibre, there appeared to be a fibroblastic response to the carbon-fibre. 
In contrast to the clinical impression of synovitis in the 10 that had a biopsy, only five showed histological evidence of chronic synovial inflammation. In most cases, the inflammation was mild and the changes were quite distinct from inflammation occurring after breakdown of the skin over superficial knots of carbon-fibre.

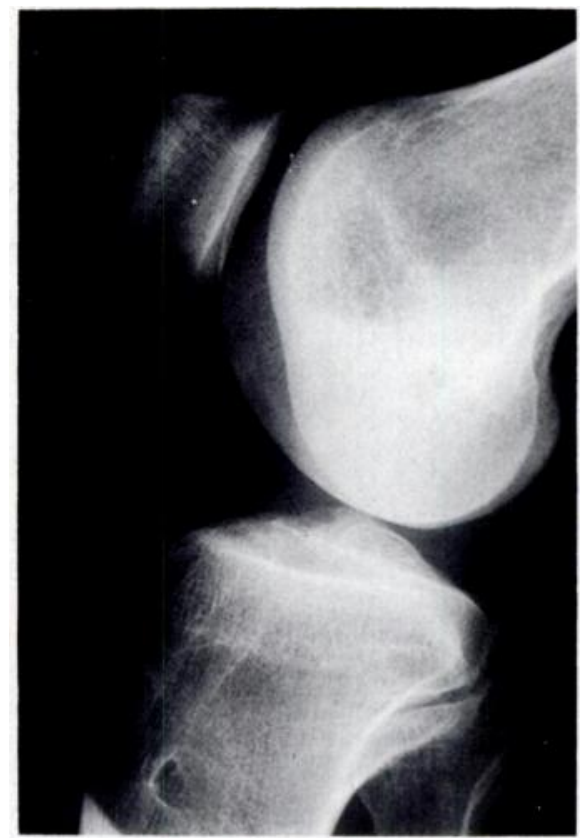

Fig.

Lateral radiograph of knee showing corticated holes in tibia and femur.

A consistent feature was papillary proliferation of the synovium seen in relation to the particles of carbonfibre. A mild foreign-body giant-cell reaction to the carbon-fibre filaments was also a constant finding. Haemosiderin was seen in surface cells of the synovium, in macrophages and around some fragments of carbonfibre.

\section{DISCUSSION}

Carbon-fibre has been recommended as a suitable material for the replacement of ligaments, including the anterior cruciate ligament (Jenkins et al. 1977; Forster et al. 1978; Jenkins 1978; Vaughan and Edwards 1978; Littlewood 1979; Vaughan 1979; Denny and Goodship 1980; Jenkins and McKibbin 1980; Tayton, Phillips and Ráliš 1982). In our series we have not been able to demonstrate the creation of a "new ligament" through augmentation of the carbon-fibre tow by organised fibroblasts. At best the carbon-fibre was covered by a thin, fibrous sheath.

Some of the patients made less satisfactory progress after replacement of the anterior cruciate ligament than patients who had had a similar procedure using materials other than carbon-fibre (Dandy, Flanagan and Steenmeyer 1982). Persistent effusion and synovial thickening were commonly seen after repair with carbon-fibre and were present in all who had arthroscopy and biopsy. These complications were attributed to the presence of carbon-fibre within the joint. The synovitis subsequently settled after biopsy, many months after the original operation. All of the patients had a negative pivot shift test after repair so that synovitis secondary to gross instability was not likely. Breakdown of the skin over the subcutaneous knots of carbon-fibre was seen but produced no serious complication after the carbon-fibre was removed.

The strength of the repair depended on the integrity of the carbon-fibre tow rather than its ability to induce the formation of a natural, replacement ligament. There appeared to be no bonding where the carbon-fibre passed through the bone, and the enlargement of the bony tunnel raised the possibility that the carbon-fibre was abrading the bone. Unless there is secure extra-articular soft-tissue fixation of the carbon-fibre there is a possibility that the carbon-fibre could slip.

We would like to acknowledge the secretarial help of Miss S. J. Whitehouse and the assistance given by various pathologists at Newmarket General Hospital and Addenbrooke's Hospital.

\section{REFERENCES}

Dandy DJ, Flanagan JP, Steenmeyer V. Arthroscopy and the management of the ruptured anterior cruciate ligament. Clin Orthop 1982:167: 43-9.

Denny HR, Goodship AE. Replacement of the anterior cruciate ligament with carbon fibre in the dog. J Small Anim Pract 1980:21:279-86.

Forster IW, Ráliš ZA, McKibbin B, Jenkins DHR. Biological reaction to carbon fibre implants: the formation and structure of a carbon-induced "neotendon". Clin Orthop 1978;131:299-307.

Ireland J, Trickey EL. MacIntosh tenodesis for anterolateral instability of the knee. J Bone Joint Surg [Br] 1980:62-B:340-5.

Jenkins DHR. The repair of cruciate ligaments with flexible carbon fibre: a longer term study of the induction of new ligaments and of the fate of the implanted carbon. J Bone Joint Surg [Br] 1978;60-B:520-2.

Jenkins DHR, Forster IW, McKibbin B, Ráliš ZA. Induction of tendon and ligament formation by carbon implants. J Bone Joint Surg [ Br] 1977: 59-B:53-7.

Jenkins DHR, McKibbin B. The role of flexible carbon-fibre implants as tendon and ligament substitutes in clinical practice. J Bone Joint Surg $[\mathrm{Br}]$ 1980;62-B:497-9.

Littlewood HF. Treatment of sprained tendons in horses with carbon fibre implants. Vet Rec 1979:105:223-4.

Tayton K, Phillips G, Ráliš Z. Long-term effects of carbon fibre on soft tissues. J Bone Joint Surg [Br] 1982;64-B:112-4.

Vaughan LC. Muscle and tendon injuries in dogs. J Small Anim Pract 1979;20 (12):711-36.

Vaughan LC, Edwards GB. The use of carbon fibre (Grafil) for tendon repair in animals. Vet Rec 1978; 102 (13):287-8. 